Zita Tomčíková', Anna Ujhelyiová2, Peter Michlík', Štefan Krivoš1, Marcela Hricová2 ${ }^{1}$ Research Institute for Man-Made Fibres, a. S., Štúrova 2, 05921 Svit, Slovak Republic 2Slovak University of Technology in Bratislava, Faculty of Chemical and Food Technology, Institute of Natural and Synthetic Polymers, Radlinského 9, 81237 Bratislava, Slovak Republic

\title{
Structure and Properties of Polypropylene Fibres Modified with Photoluminescent Pigment as a Tool for the Protection of Original Products \\ Struktura in lastnosti s fotoluminiscentnim pigmentom modificiranih polipropilenskih vlaken, namenjenih varovanju originalnosti izdelkov
}

Original Scientific Article/lzvirni znanstveni članek

Received/Prispelo 08-2017 • Accepted/Sprejeto 08-2017

\begin{abstract}
A special photoluminescent inorganic pigment was used as a tool to protect polypropylene (PP) fibre originality. The effect of pigment content and uniaxial deformation on the supermolecular structure and basic mechanical properties of PP fibres modified with the above-mentioned pigment were investigated, together with its colour performance under a UV lamp. Supermolecular structure parameters, such as birefringence, sound velocity in fibres, crystallinity and the crystallinity index of undrawn and drawn modified PP fibres prepared using a discontinuous technological process, were studied. Mechanical properties such as fineness, Young's modulus, tenacity at break and elongation at break of undrawn and drawn modified fibres were evaluated. The obtained experimental results of modified PP fibres were compared with the supermolecular structure and mechanical characteristics of standard unmodified PP fibres prepared under same technological conditions.

Keywords: protective photoluminescent pigment, modified PP fibres, structure, mechanical properties, counterfeiting, product protection
\end{abstract}

\section{Izvleček}

Poseben fotoluminiscenčni anorganski pigment je bil uporabljen za varovanje izvirnosti polipropilenskih vlaken (PP). Raziskani so bili vpliv vsebnosti teh pigmentov v modificiranih PP vlaknih in njihovega raztezanja na nadmolekulsko strukturo, osnovne mehanske lastnosti in učinkovitost barve pod UV svetilko. Na neraztezanih in raztezanih modificiranih PP vlaken, izdelanih v diskontinuirnem tehnološkem postopku, so bili proučeni parametri nadmolekulske strukture dvolomnosti, hitrosti zvoka v vlaknih, kristaliničnosti in indeks kristaliničnosti ter mehanske lastnosti, kot so finoča, Youngov modul, pretržna sila in pretržni raztezek. Dobljeni eksperimentalni rezultati modificiranih PP vlaken so bili primerjani z nadmolekulsko strukturo in mehanskimi lastnostmi standardnih nemodifciranih PP vlaken, izdelanih pri enakih tehnoloških pogojih.

Ključne besede: varovalen fotoluminiscenten pigment, modificirana PP vlakna, nadmolekulska struktura, ponarejanje, varovanje izdelkov 


\section{Introduction}

Polypropylene (PP) is presently one of the most widely used thermoplastic materials [1-5]. PP is a good polymer for the matrix, due to its good mechanical properties, easy processing and its low price [6].

A large number of counterfeits of original products have been identified in recent years in all sectors of industry, such as automotive and machine parts, technical components, plastic products, fashion and fashion accessories, perfumes, drugs, labels, logos, revenue stamps, etc. It is practically impossible to distinguish between original products and their fake counterparts. Companies worldwide are losing billions of euros, and therefore attempt to effectively protect their products against counterfeiting [7]. There are many visible and invisible identifying marks on the market, but many of them do not represent a hurdle for counterfeiters. Some established product marks are very efficient, but are difficult to implement because their implementation is a complex and expensive process [7]. The application of luminescent pigments represents one cost-acceptable solution for the protection of original products [7]. As a rule, luminescent materials emit light $[8,9]$. There are several kinds of luminescence, depending on the manner of excitation. They include photoluminescence (excited by light) [10-13], thermoluminescence (due to heat), optoluminiscence (multiplied also by the conduction of light) [14], electroluminescence (the activator is an electric field), chemiluminescence (excited by chemical reactions), radioluminescence (due to ionising radiation), mechanoluminescence (created by mechanical effects, such as friction, pressure, etc.) and crystalloluminescence (produced during crystallisation). However, mainly photoluminescent pigments are of interest for fibres. They can be divided into: fluorescent, $[10,11]$ with a short luminescence decay time of only a few nanoseconds, and phosphorescent with a long luminescence decay time, which can take a few minutes or hours [15].

Today it is possible to prepare pigments with a photonic effect based on inorganic phosphors that emit light in a precisely defined pattern to match the needs of the intended application [7]. Counterfeiters have practically no information concerning product protection or about the identification thereof. The utilisation of these pigments may therefore be a good way to protect original products [7].
In this study, the effect of the content of pigment and uniaxial deformation on the supermolecular structure and basic mechanical properties of polypropylene fibres modified with photoluminescent pigment from the company Tailorlux $\mathrm{GmbH}$ were investigated, together with its different colour performance before and after illumination with a UV lamp. Undrawn and drawn modified PP fibres were prepared using a discontinuous POY technological process. The results obtained from PP fibres modified with the pigment from Tailorlux were compared with PP fibres without a photoluminescent pigment prepared under the same technological conditions.

\section{Experimental}

\subsection{Materials}

Isotactic polypropylene (iPP) produced by Slovnaft (Slovakia) with a melt flow rate (MFR) of $27.6 \mathrm{~g} / 10 \mathrm{~min}$ and a special photoluminescent inorganic pigment from Tailorlux GmbH (Germany) were used. A PP masterbatch of pigment developed by the Research Institute for Man-Made Fibres, a.s. Svit (pigment content of $1.0 \mathrm{wt} . \%, \mathrm{MFR}=10.0 \mathrm{~g} / 10 \mathrm{~min}$, filter index $<50 \mathrm{MPa} / \mathrm{kg}$, according to EN 13900-5) was used during the preparation of modified fibres.

\subsection{Fibre preparation}

The modified PP fibres were prepared from a mechanical mixture of PP and a PP masterbatch of photoluminescent pigment using the traditional discontinuous process of spinning and drawing. The laboratory discontinuous line had an extruder with a diameter of $32.0 \mathrm{~mm}$, with a discontinuous onestep drawing process. The following constant processing conditions were used: a spinning temperature of $220^{\circ} \mathrm{C}$, a spinning die plate of $2 \times 25$ holes with a diameter of $0.3 \mathrm{~mm}$, a final spinning process speed of $1500 \mathrm{~m} / \mathrm{min}$, a drawing ratio of $\lambda=2.0$, a drawing temperature of $130^{\circ} \mathrm{C}$ and a final drawing process speed of $100 \mathrm{~m} / \mathrm{min}$.

\subsection{Methods used}

\section{Fibre birefringence - total orientation of fibres}

The orientation of macromolecular chains in fibres expresses the level of anisotropy of an oriented polymer system (fibre). The total orientation of prepared PP and modified PP fibres was evaluated using a DNP 714BI polarisation microscope, 
where the refractive indices of light in the fibre axis $\left(n_{\|}\right)$and in the perpendicular direction of the fibres $\left(n_{\perp}\right)$ were identified. The fibre's birefringence $(\Delta n)$ was calculated from these value using Equation 1:

$\Delta n=n_{\|}-n_{\perp}$

\section{Sound velocity in fibres}

The sound velocity in fibres is given as the ratio of fibre length to the time needed for the transfer of acoustic nodes along that length (expressed in $\mathrm{km} / \mathrm{s}$ ). It is dependent on the internal structure arrangement of fibres (expressed by a supermolecular structure parameter) and may serve as a measure of fibre anisotropy. The sound velocity in PP and modified PP fibres was measured using a PPMSR Dynamic Modulus Tester (USA).

\section{Crystallinity index (FT-IR)}

The crystallinity index $\left(I_{k}\right)$ of PP fibres represents the fraction of the crystalline phase in PP fibres. It is determined as the ratio of the integrated absorbance of the absorption band of $840 \mathrm{~cm}^{-1}\left(A_{i 840}\right)$, characterising the regularity of the arrangement of macromolecular chains segments, to the integrated absorbance of the absorption band of $2723 \mathrm{~cm}^{-1}$ $\left(A_{i 2723}\right)$, as the internal standard effecting the degree of crystallinity (Equation 2):

$I_{k}=\frac{A_{i 840}}{A_{i 2723}}$

The crystallinity index of modified and unmodified PP fibres was evaluated using a Shimadzu 8400 FTIR spectrophotometer.

\section{Crystallinity of fibres}

Crystallinity $(\beta)$ represents the crystalline portion of fibres and may be evaluated using various methods. In this work, a Perkin Elmer DSC 4 device was used for the evaluation of the thermal properties of unmodified PP and modified PP fibres according to STN EN ISO 3146/AC. A non-isothermal analysis process was performed in this procedure. A sample of original fibre was heated at a rate of $10{ }^{\circ} \mathrm{C} / \mathrm{min}$ from 50 to $220^{\circ} \mathrm{C}$. All measurements were carried out in a nitrogen atmosphere. The melting enthalpy $\left(\Delta H_{m}\right)$ from the melting endotherm of the first heating was determined, and was used for the calculation of crystallinity $(\beta)$ using Equation 3:
$\beta=\frac{\Delta H_{m}}{\Delta H_{m, 0}} \times 100[\%]$

where $\Delta H_{m, 0}=198.11 \mathrm{~kJ} / \mathrm{kg}$ is the melting enthalpy of PP with a crystallinity of $100 \%$.

\section{Mechanical properties of fibres}

The mechanical properties of unmodified and modified PP fibres were measured using an Instron 3343 device (USA) with a gauge length of $125 \mathrm{~mm}$ and clamping rate of $500 \mathrm{~mm} / \mathrm{min}$. An average of at least 10 individual measurements was used for each fibre. The mechanical characteristics (tenacity at break, elongation at break and Young's modulus) and fineness were determined according to ISO 2062:1993 and STN EN ISO 1973, respectively.

\section{Results and discussion}

The stability of the spinning and drawing process of the studied $\mathrm{PP} /$ photoluminescent pigment system over the entire evaluated concentration range of the pigment (0.005-0.5 wt.\%) was comparable with the stability of the unmodified standard PP. It follows that the studied modified system is fibre-forming and processes stably over the entire concentration range of the photoluminescent pigment.

The supermolecular structure parameters and basic mechanical properties of unmodified and modified PP fibres were evaluated.

Figures 1 and 2 show the effect of various photoluminescent pigment content on the supermolecular structure parameters of undrawn and drawn modified PP fibres.

In the case of undrawn modified PP fibres, there was a tendency of a slight decrease in the total average orientation of macromolecular chains in the PP matrix (Figure 1a), and in increase of the orientation of PP macromolecular chains in surface layers (Figure 1b) with an increased content of the photoluminescent pigment in the fibres. At the same time, there was a slight decrease in the crystalline phase (Figure 2a) when pigment content was below $0.2 \mathrm{wt} . \%$, as well as the crystalline portion (Figure 2b) for pigment content below $0.1 \mathrm{wt} . \%$ in the PP matrix of undrawn modified PP fibres. This was the consequence of inorganic pigment particles, as they inhibit the orientation of PP macromolecular chains in the direction of the fibre axis in the spinning zone. 


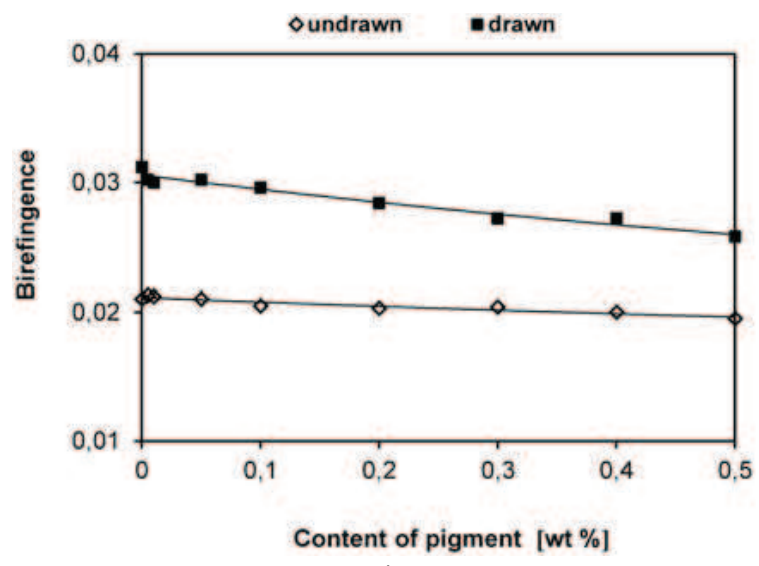

a)

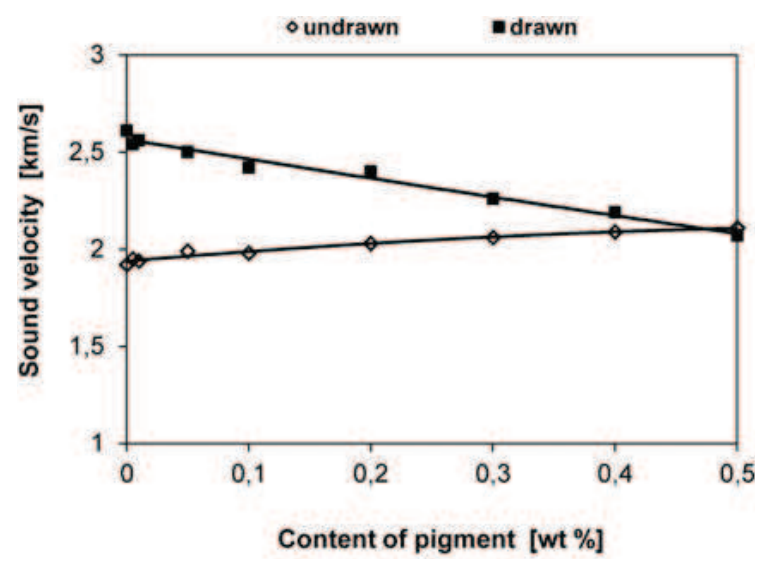

b)

Figure 1: Dependence of birefringence (a) and sound velocity (b) of undrawn and drawn modified PP fibres on photoluminescent pigment content

The uniaxial deformation of undrawn modified PP fibres significantly increased birefringence over the entire evaluated range of pigment content (Figure 1a), while sound velocity increased to the level of $0.4 \mathrm{wt} . \%$ of pigment content (Figure 1b) in the drawn modified PP fibres against undrawn fibres. At the same time, there was a slight increase in the index crystallinity to the level of $0.3 \mathrm{wt} . \%$ (Figure 2a), while crystallinity increased to the level of 0.4 wt.\% of pigment content (Figure 2b). This was the result of the effect of external stress on the orientation of macromolecular chains in the polymer matrix in the direction of the fibre axis during the drawing process. On other hand, the increased pigment content in the drawn modified PP fibres resulted in a decrease in all of the above-mentioned parameters compared with the drawn unmodified PP fibres. This was due to the fact that

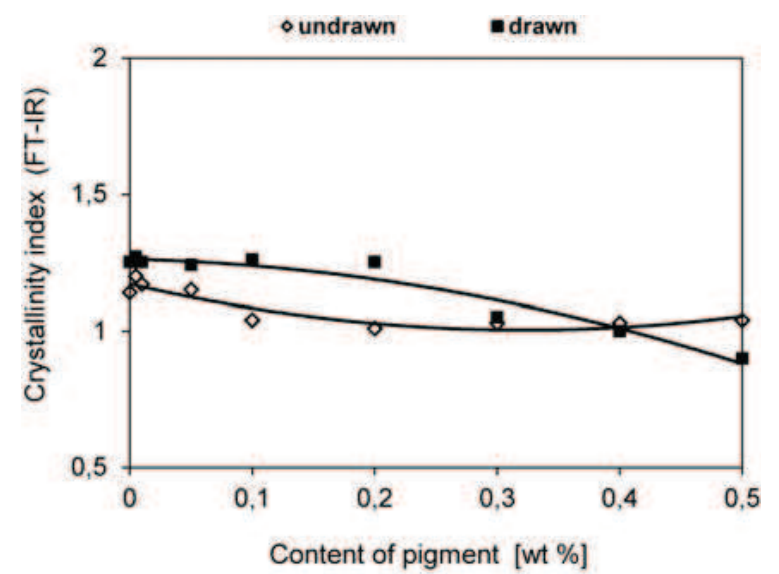

a)

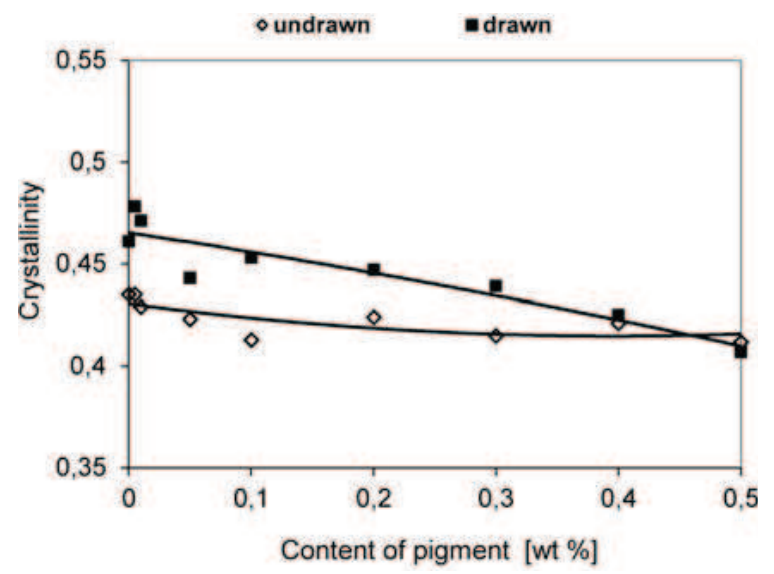

b)

Figure 2: Dependence of the crystallinity index (FT-IR) (a) and crystallinity (b) of undrawn and drawn modified PP fibres on photoluminescent pigment content

higher inorganic pigment content decreases the orientation of macromolecular chains in the direction of the fibre axis in drawn fibres due to the steric braking effect of inorganic pigment particles.

Figures 3 and 4 show the effect of the photoluminescent inorganic pigment content on the basic mechanical properties of undrawn and drawn modified PP fibres. The photoluminescent pigment content in the evaluated range (from 0.005 to $0.5 \mathrm{wt} . \%$ ) had no significant effect on the fineness of undrawn and drawn modified PP fibres when compared with unmodified PP fibres (Figure 3a).

Increased photoluminescent pigment content in the mass of undrawn PP fibres resulted in a slight decrease in their tenacity ( $\max 25 \%$ from original value, Figure 4a) while elongation increased (approximately $100 \%$ in absolute terms from original value, Figure $3 b$ ) compared with undrawn unmodified PP 


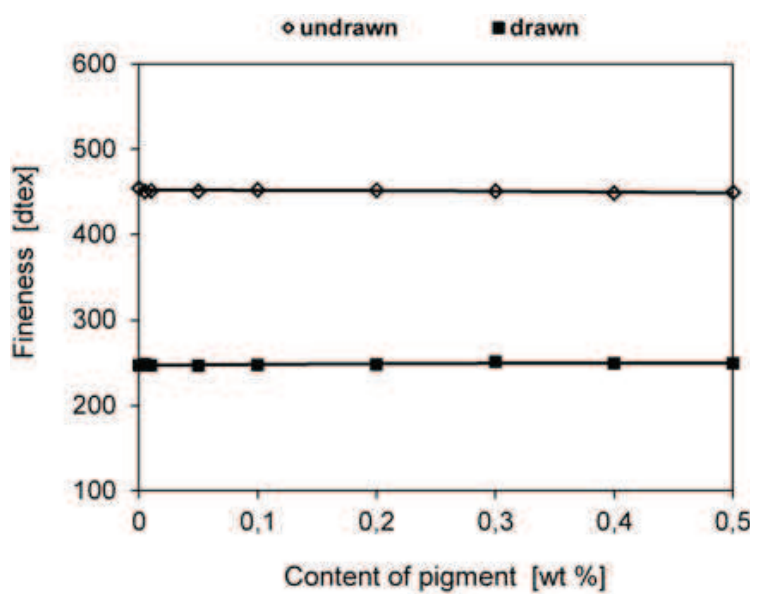

a)

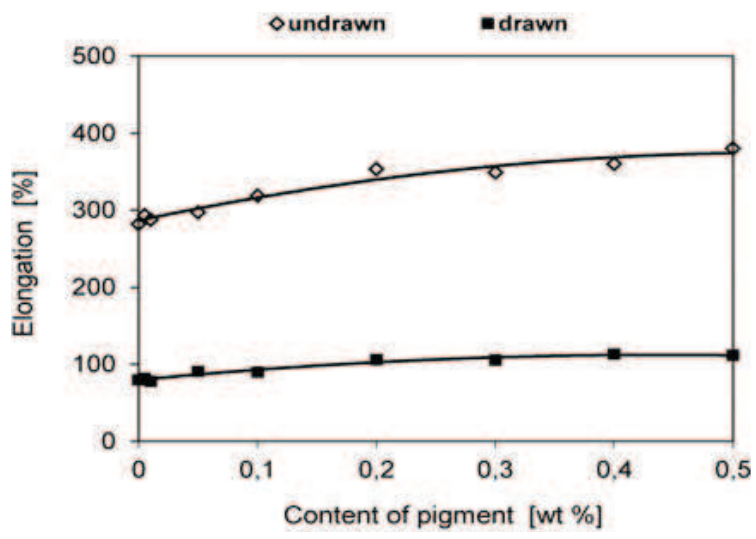

b)

Figure 3: Dependencies of fineness (a) and elongation at break (b) of undrawn and drawn modified PP fibres on photoluminescent pigment content

fibres. This was linked to the slight decrease in the total average orientation of macromolecular chains in the PP matrix (Figure 1a) and in the crystalline portion $\beta$ (Figure $2 \mathrm{~b}$ ) at increased photoluminescent pigment content in the mass of undrawn modified fibres. At the same time, there was an increase in Young's modulus (approximately 70\% from original value, Figure $4 \mathrm{~b}$ ). This was the result of an increase in the orientation of macromolecular chains in the surface layers of undrawn fibres (Figure 1b). The uniaxial deformation of undrawn modified fibres on the drawing ratio of $\lambda=2$ significantly increased the tenacity (Figure $4 \mathrm{a}$ ) and decreased the elongation at break (Figure $3 \mathrm{~b}$ ) of fibres over the entire evaluated range of photoluminescent pigment content in drawn fibres when compared with undrawn PP fibres. This was mainly the result of a significant increase in the total average orientation of

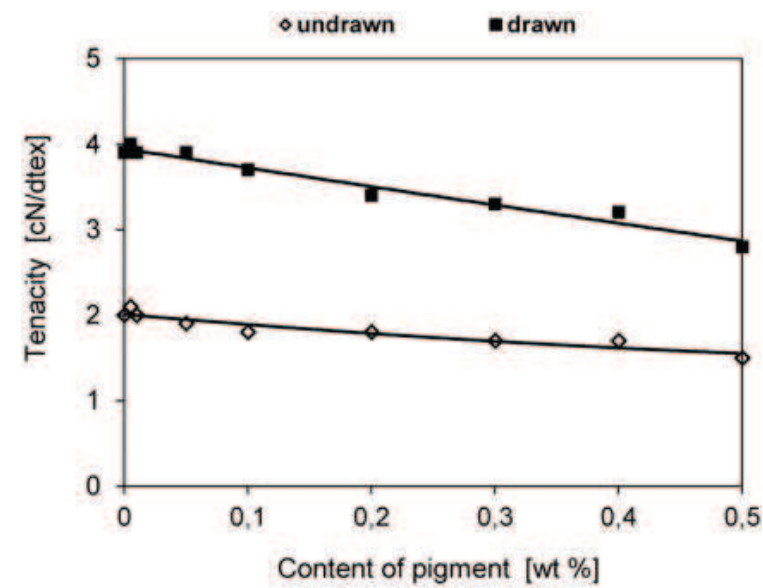

a)

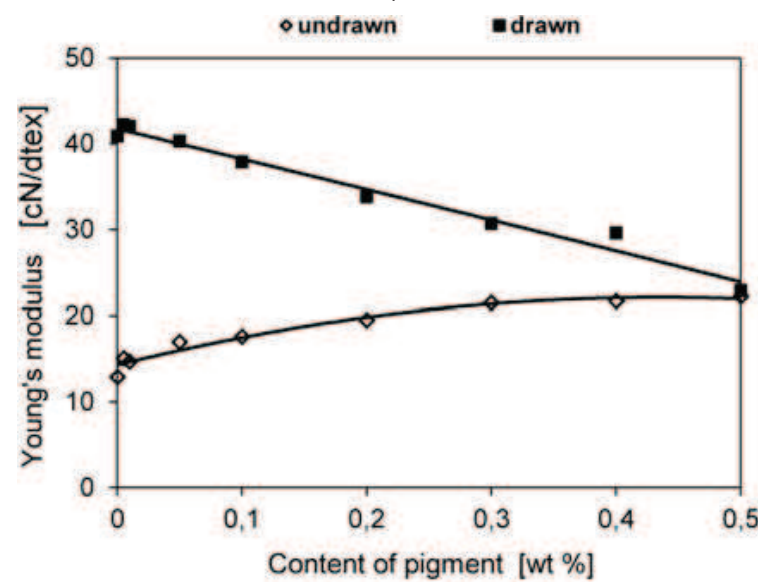

b)

Figure 4: Dependencies of tenacity at break (a) and Young's modulus (b) of undrawn and drawn modified PP fibres on photoluminescent pigment content

macromolecular chains in the polymer matrix (Figure 1a) and an increase in the orientation of PP macromolecular chains in surface layers (Figure 1b).

The addition of a photoluminescent pigment in the modified PP fibres decreased the regularity of the arrangement of macromolecular chains in drawn modified systems. This was reflected in a decrease in their tenacity ( $\max 28 \%$ from original value, Figure $4 \mathrm{a}$ ) and Young's modulus (max 44\% from original value, Figure $4 \mathrm{~b}$ ) compared with drawn unmodified PP fibres, and a simultaneous slight increase in their elongation (approximately 30\% in absolute terms from original value, Figure $3 \mathrm{~b}$ ) with increased photoluminescent pigment content in the drawn PP fibres. This was related to the decrease in all evaluated supermolecular structure parameters (Figures 1 and 2) with increased photoluminescent pigment content in the drawn modified PP fibres. 


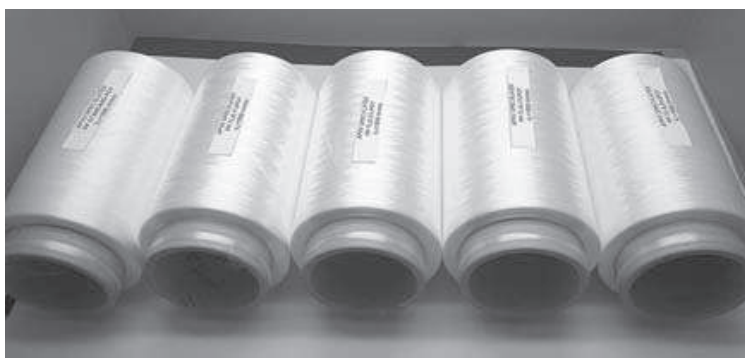

a)

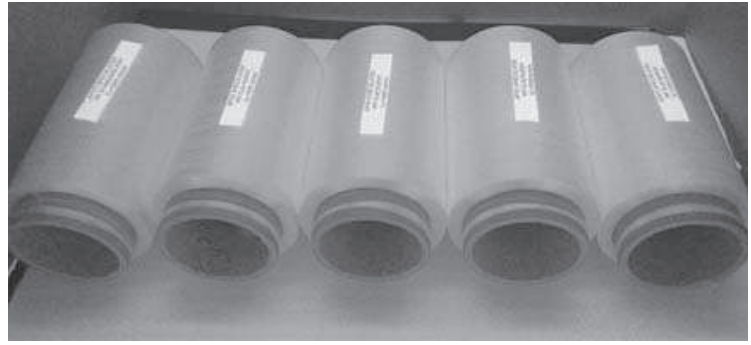

b)

Figure 5: Effect of photoluminescent pigment with a content of $0.1 ; 0.2 ; 0.4$ and $0.5 w t . \%$ on the colour performance of undrawn modified PP fibres compared with unmodified PP fibre (first from the left) under daylight D65 (a) and under a UV lamp (b)

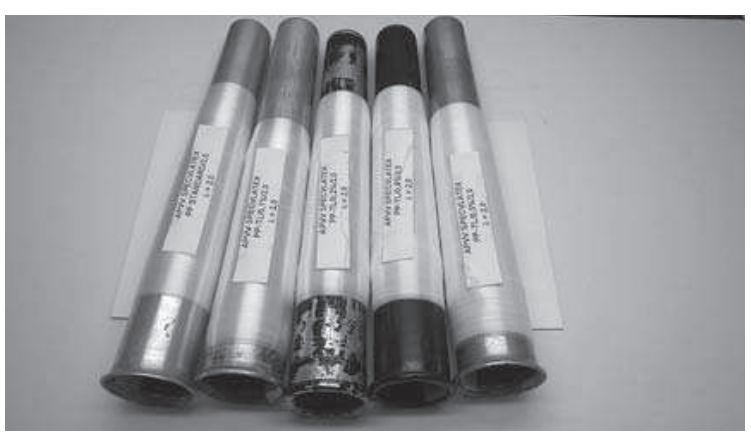

a)

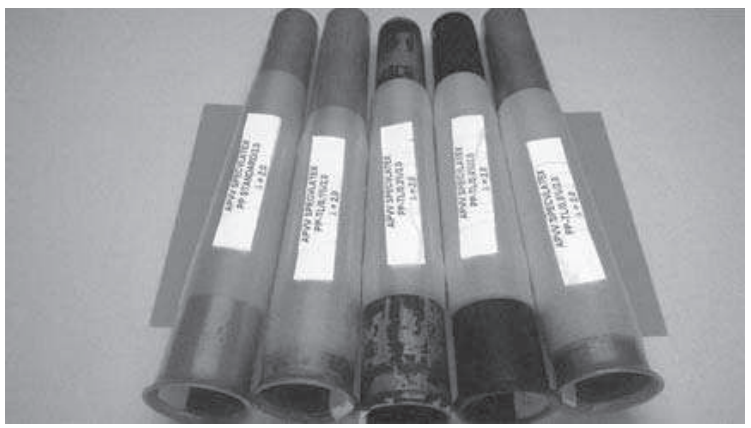

b)

Figure 6: Effect of photoluminescent pigment with a content of $0.1 ; 0.2 ; 0.4$ and $0.5 \mathrm{wt}$.\% on the colour performance of drawn modified $P P$ fibres compared with drawn unmodified PP fibre $(\lambda=2.0)$ (first from the left) under daylight D65 (a) and under a UV lamp (b)
The mechanical properties of modified PP fibres correlate well with their supermolecular structure parameters.

Figures 5 and 6 show the effect of the photoluminescent pigment content on the colour performance of undrawn and drawn $(\lambda=2.0)$ modified PP fibres under a UV lamp.

Figures 5a and 6a clearly show that all prepared modified PP fibres (undrawn and drawn) are white under daylight (D65). Under the UV lamp there is white only unmodified standard PP fibre (undrawn in Figure $5 b$ and drawn in Figure 6b) while the modified PP fibres turn red. Colour intensity increases as the content of photoluminescent pigment in PP fibres is increased.

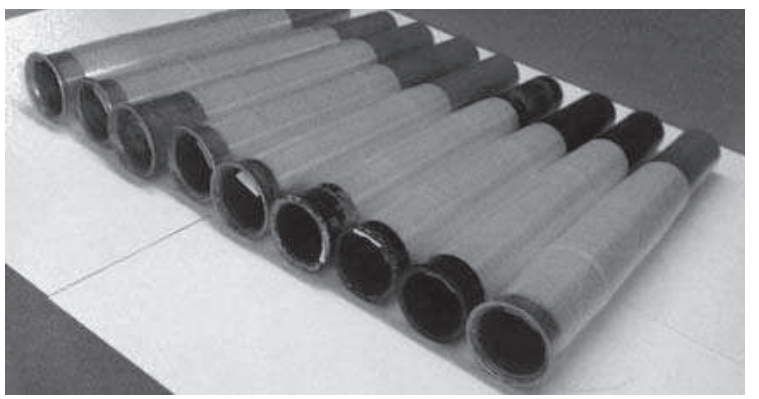

Figure 7: Effect of photoluminescent pigment with a content of $0.005 ; 0.01 ; 0.05 ; 0.1 ; 0.2 ; 0.3 ; 0.4$ and 0.5 wt.\% on the colour performance of drawn modified PP fibres compared with drawn unmodified standard PP fibre $(\lambda=2.0)$ (first from the left) under a UV lamp

It is evident from Figure 7 that even a low content (about $0.10 \mathrm{wt}$ \%, sample 5 from left to right) of the evaluated photoluminescent pigment provides a clearly visible colour change under a UV lamp. Lower contents of photoluminescent pigment $(<0.1 \mathrm{wt} . \%)$ can be measured via UV detection equipment, such as a hand-held scanner or lab spectrometer.

\section{Conclusion}

The stability of the spinning and drawing process of the studied PP/ photoluminescent pigment system over the entire evaluated concentration range of pigment (0.005-0.5 wt.\%) was comparable with the stability of unmodified standard PP. It follows that the studied modified polymer system is fibre-forming and processes stably over the entire concentration 
range of photoluminescent pigment. The basic dependencies of photoluminescent pigment content and uniaxial deformation on supermolecular structure parameters, together with the basic mechanical properties of undrawn and drawn modified PP fibres, were evaluated. It was determined that the particles of the inorganic pigment inhibit the orientation of PP macromolecular chains in the direction of the fibre axis in the spinning zone and in the process of uniaxial deformation. This was seen as a reduction in parameters relating to the orientation of the supermolecular structure of drawn fibres and the mechanical properties (tenacity and Young's modulus) of drawn modified PP fibres due to the increased content of pigment in PP fibres. On the other hand, uniaxial deformation significantly increased the tenacity and Young's modulus of fibres over the entire evaluated range of photoluminescent pigment content in drawn modified fibres compared with undrawn PP fibres. From a procedural and technological point of view, the evaluated photoluminescent pigment can be used as tool for the protection of original products, as even a low content (about 0.10 wt.\%) of the evaluated photoluminescent pigment provides a clearly visible colour change under a UV lamp. Lower contents of photoluminescent pigment $(<0.1 \mathrm{wt} . \%)$ are measured via UV detection equipment, such as a hand-held scanner of lab spectrometer, where optical excitation creates an individual spectral pattern that facilitates unambiguous authentication. The resulting spectral information can be digitised and thus compared with recorded reference data.

\section{Acknowledgement}

This work was supported by the Slovak Research and Development Agency under contract no. APVV-140175.

\section{References}

1. GAHLEITNER, Marcus, PAULIK, Christian. Chapter 11 - Polypropylene and other polyolefins. Brydson's plastics materials. Eighth edition, 2017, pp. 279-309, doi: 10.1016/B978-0-32335824-8.00011-6.

2. Global fiber production. Chemical Fibers International, 2016, 66(3), 100-102.

3. Global fiber production. Chemical Fibers International, 2014, 64(3), 116-118.
4. Global man-made fiber production: continued growth. Chemical Fibers International, 2014, 64(2), 60 .

5. EU-28, steady fiber imports in 2015, Melliand International. Worldwide Textile Journal, 2016, 3, 132.

6. PANAITESCU, Denis Mihaela, NICOLAE, Cristian Andi, VULUGA, Zina, VITELARU, Catalin, SANPOREAN, Catalina Gabriela, ZAHARIA, Catalin, FLOREA, Dorel, VASILIEVICI, Gabriel. Influence of hemp fibers with modified surface on polypropylene composites. Journal of Industrial and Engineering Chemistry, 2016, 37, 137-146, doi: 10.1016/j.jiec.2016. 03. 018.

7. Tailorlux GmbH [online], [accessed 21. 03. 2017]. Available on World Wide Web: <http:// en.tailorlux.com>.

8. LIN, Yan, YIN, Jun, YUAN, Jingjing, HU, Ming, LI, Ziyong, YU, Guang-Ao, LIU, Sheng Hua. Synthesis, chracterization and properties of binuclear gold(I) phosphine alkynyl complexes. Organometallics, 2010, 29(12), 2808-2814, doi: 10.1021/om1000919.

9. KRASOVITSKII, B. M., BOLOTIN, B. M. Organic luminescent materials. New York : VCH Publishers, 2002.

10. BAMFIELD, Peter. Chromic phenomena. Technological aplications of colour chemistry. Cambrige : RSC Publishing, 2001.

11. GREAVES, P. H., SAVILLE, B. P. Microscopy of textile fibres. Oxford : Bios Scientific Publishers, London : Royal Microscopical Society, 1995.

12. LAKOWICZ, Joseph R. Principles of fluorescence spectroscopy. Second edition. New York ; London : Plenum Press, 1983.

13. GRAVISSE, Philippe E., VAN SCHOOTE, Jacques F. Photoluminescent textile materials. US Patent, No. 4211813.

14. ALIPRANDI, Stefano, MONTICELLI, Carol, ZANELLI, Alessandra. Technical textiles and thin insulation materials. New scenarios for the energetic retrofitting. Energy Procedia, 2015, 78, 501-506, doi: 10.1016/j.egypro.2015.11.716.

15. SPRINGSTEEN, Arthur W. Fluorescence and color [online], Labsphere [accessed 3. 10. 2017]. Available on World Wide Web: <http://www. dfisica.ubi.pt/ hgil/FotoMetria/PDF\%27sDOC\%27s/Labsphere/Fluorescence-20and-20color.pdf>. 